\title{
Estetika Eeewahh dalam Rentak Joget
}

\author{
Rivaldi Ihsan, Asril ${ }^{1}$, dan Wilma Sriwulan \\ Penciptaan dan Pengkajian Seni, Pascasarjana ISI Padangpanjang
}

\begin{abstract}
The Aesthetics of Eeewahh in Rentak Dance. The research aims to explore the aesthetic concept of eeewahh in rentak joget of Orkes Melayu Pancaran Senja (OMPS) at Kampung Melayu, Batu Besar, Batam. Data was obtained by observing the performance of OMPS. Eeewahh is an aesthetic phenomenon found in a singer who experiences the feeling of fun, joy, or amazement when she is in the climactics moment at the melodious interluding part of rentak joget rhyme. In such a moment the utterance of eeewahh is arisen as the expression of joyful emotion. Eeewahh is risen up by both external and internal factor. The external factor covers the stage of musical performances, musical instruments, and musicians. And the internal factor covers logogenic musical concept, tritonic, metronomic tempo of 120 , bar $6 / 8$, and the expression of admiration, joy, and laughter.
\end{abstract}

Keywords: Eeewahh; Rentak dance; Pancaran Senja

\begin{abstract}
ABSTRAK
Penelitian ini, bertujuan menggali konsep estetis eeewahh dalam rentak joget studi kasus pada Orkes Melayu Pancaran Senja (OMPS) dalam masyarakat Kampung Melayu Batu Besar Batam. Data diperoleh melalui pengamatan terlibat pada pementasan OMPS. Berdasarkan penelitian dapat disimpulkan bahwa Eeewahh merupakan fenomena estetis dari seorang penyanyi yang mengalami suasana senang, gembira, atau takjub ketika berada dalam keadaan klimaks saat sajian melodibagian interlud dalam teks lagu pantun rentak joget. Pada suasana ini akan muncul ucapan eeewahh sebagai ungkapan emosi rasa keindahan. Eeewahh dibangun oleh faktor eksternal dan internal. Faktor eksternal meliputi kondisi panggung pertunjukan, instrumen, dan pemusik. Faktor internal meliputi konsep musik logogenik, tritonik, tempo metronom 120, sukat 6/8, ekspresi kagum, gembira, dan canda tawa.
\end{abstract}

Kata kunci: Eeewahh; Rentak joget; Pancaran Senja

\section{Pendahuluan}

Batam saat ini telah menjelma menjadi sebuah kota industri yang heterogen dihuni oleh berbagai etnik dari Nusantara, yaitu Melayu, Jawa, Minang, Batak, Madura, Sunda, Banjar, dan Bugis. Masingmasing etnis terutama para perantau membentuk organisasi-organisasi sosial yang bersifat sukuisme dan keagamaan, seperti: Paguyuban Jawa Tengah, Paguyuban Jawa Timur, Ikatan Keluarga Batak Islam (IKBI), Ikatan Keluarga Minang (IKM), Persatuan Keluarga Daerah Pariaman (PKDP) Sumatera Barat, dan beberapa nama organisasi lainnya yang menunjukkan kedaerahan masing-masing.
Para perantau, baik melalui komunitas-komunitas kecil maupun organisasi sosialnya, secara lebih luas menghadirkan seni dan budaya khas daerah masing-masing sebagai upaya memunculkan identitas mereka dalam masyarakat Batam yang beragam. Identitas individu-individu melalui budayanya hadir menjadi bagian dari identitas kolektif (Rhoads, 2010: 158; Yasin, 2015: 60).

Beragamnya penghuni Batam telah turut serta merepresentasikan seni dan budaya asal mereka masing-masing. Dinamika masing-masing etnik turut mewarnai dinamika pemunculan budaya mereka; semakin dinamis mereka, maka semakin mencuat identitas kultural mereka. Misalnya,

\footnotetext{
Alamat korespondensi: Pascasarjana ISI Padangpanjang. Jln. Bahder Johan Padangpanjang, Sumatera Barat, Indonesia - 27128. E-mail: asrilmuchtar2017@gmail.com. HP. +628126788215.
} 
Paguyuban Jawa menampilkan seni dan budaya mereka seperti wayang, kuda kepang, reog dan sebagainya; masyarakat Batak menampilkan gondang sabangunan atau opera Batak, masyarakat Minang melalui organisasi PKDP Pariaman sering sekali menampilkan pertunjukan Tabuik sebagai imitasi pertunjukan ritual Tabuik di kampung halaman mereka. Begitu juga dengan komunitaskomunitas lainnya menampilkan pula ciri khas seni dan budaya tradisi mereka masing-masing, sehingga mengancam musik tradisi Melayu, baik eksistensi maupun perkembangannya.

Halyang tampak adalah semakin berkurangnya apresiasi terhadap musik Melayu tradisi yang dimiliki oleh masyarakat Melayu Batam, bila dibandingkan dengan masa ketika para perantau di atas belum mendiami Pulau Batam. Sementara etnis Melayu adalah "tuan rumah" penduduk Kota Batam yang memiliki musik tradisi dengan ciri dan estetika yang khas pula. Spesialisasi fungsi dan diferensiasi progresif budaya adalah konsekuensi dari sosial, budaya, dan evolusi biologis masyarakat modern (Nita, 2011: 1768).

Etnis Melayu selain penduduk asli Batam, juga mendiami kawasan yang cukup luas di Pulau Sumatra dan Riau Kepulauan hingga ke Semenanjung Malaysia. Salah satu ciri kuat yang mengikat mereka dalam kesenian, khususnya musik tradisi adalah musik Melayu dengan berbagai genre. Sebagaimana dicatat oleh Martarosa, di antaranya musik gazal di Riau, musik ronggeng di Sumatra Utara, dan musik gamat di Sumatra Barat. Masing-masing musik itu saling memengaruhi dan berinteraksi yang dapat dilihat dari nada, syair, irama yang dimainkan oleh jenis musik tersebut sebagai ciri dan gaya dalam bentuk elemen-elemen yang disajikannya (Martarosa, 2016).

Genre musik Melayu yang tumbuh dan berkembang di kalangan masyarakat Melayu di Batam adalah musik Melayu yang mirip dengan musik ronggeng di Sumatra Utara dan dondang sayang di Semenanjung Malaysia. Salah satu grup musik yang masih eksis hingga saat ini adalah OMPS yang terdapat di Kampung Melayu Batu Besar. Orang-orang Batam mengekspresikan suasana batin mereka melalui musik orkes ini. Dalam hal ini, musik dapat merepresentasikan unsur penting dalam mengkonstruksi makna pergerakan sosial dan dalam membuat dan mengorganisasi identitas kolektif kelompok masyarakat tersebut (Pierobon, 2014: 40; Makale \& Article, 2015; Ustun Topal, Korkut, \& Kiper, 2016; Nanni, 2014: 41-42). Kelompok musik Orkes Melayu Pancaran Senja terkenal berperan penting di Pulau Batam, sebagai representasi identitas seni budaya masyarakat Melayu Pesisir Batam.

Sebutan Orkes Melayu pada awal nama grup ini mencirikan pada genre musik mereka. Orkes Melayu adalah suatu kelompok musik terdiri dari lima sampai sepuluh orang bermain musik, ritme, melodi, harmoni mengiringi syair berbahasa Melayu yang diwujudkan dalam konsep beat khas Melayu yang disebut rentak. Jenis rentak yang umum dikenal dalam musik Melayu adalah rentak langgam, rentak inang, rentak zapin, dan rentak joget (Takari \& Dewi, 2008). Rentak digunakan sebagai kesepakatan dalam memainkan jenis-jenis musik Melayu, termasuk oleh masyarakat Kampung Melayu Batu Besar.

Pertunjukan musik Orkes Melayu Pancaran Senja (OMPS) selalu memainkan lagu-lagu Melayu berentaklanggam, rentak inang, rentak zapin, dan rentak joget. Pemilihan rentak menjadi kesepakatan sesama pemusik OMPS. Masing-masing rentak memiliki rasa yang berbeda. Rentak langgam dengan meter empat pada bagian awal dan di bagian akhir dengan meter enam bersifat sedih, syahdu, lambat;rentak inang dengan meter empat, bersifat di antara lambat dan cepat atau sedang; rentak zapin dengan meter empat bersifat nyanyian moral dan religius (Takari dan Dewi, 2008: 123); dan rentak joget dengan meter enam bersifat rancak, cepat, dan gembira.

Suatu hal yang menarik dalam setiap pertunjukan OMPS ketika lagu-lagu rentak joget sedang berlangsung. Respons tubuh pemusik, penyanyi, dan penonton ingin bergerak atau berjoget mengikuti irama musik hingga kemudian mereka melakukannya. Pertunjukan itu sendiri merupakan aksi yang memproduksi makna, dan metafor pertunjukan yang terkait dengan tingkah laku manusia hingga konteks yang lebih luas lagi (Santi, 2017: 92; Widdess, 2012: 89; Lewis, 2012: 98). Peristiwa ini seperti mengajak semua orang yang hadir pada 
saat pertunjukan untuk bergembira sejenak tanpa ada paksaan.Pada situasi ini eeewahh muncul yang berasal dari suara penyanyi dan kadang-kadang dari penonton, seakan-akan menunjukkan rasa senang dan gembira yang sedang mereka nikmati. Apakah ini sebagai ungkapan dari puncak rasa senang yang mereka rasakan saat menikmati lagu dalam rentak joget? Hal ini masih menimbulkan pertanyaan bagi peneliti. Pertanyaan yang muncul adalah mengapa eeewahh hadir dalam rentak joget?

\section{Orkes Melayu Pancaran Senja dan Struktur Lagu dalam Pertunjukan}

Masyarakat Melayu Pulau Batam mengenal Orkes Pancaran Senja melalui acara adat Melayu, khitanan, pernikahan, serta pertunjukan rutin hari Minggu pukul 10.00 pagi hingga siang di Pantai Melayu Batu Besar. Diluar jadwal itu grup musik ini melakukan pertunjukan dalam konteks adat dan sosial. Musik memiliki arti dan makna sehingga dapat dipahami dengan mempertimbangkan konteks sosial atau budaya terkait jenis musik tertentu diberlakukan (Barnard, 2012: 69; Rasic, 2016). OMPS konsisten menyajikan lagu-lagu Melayu sebagai identitas mereka, dan secara tidak langsung turut melestarikan seni budaya (musik) Melayu Kepulauan.

Rahman adalah pimpinan grup dan tokoh yang berperan penting dalam mendirikan dan mempertahankan Orkes Melayu Pancaran Senja. Pada mulanya grup musik ini bernama Orkes Melayu Bunga Rampai yang didirikan oleh Rahman pada tahun 1998 di Pulau Ngenang. Pertengahan bulan Juni tahun 2007 Rahman meninggalkan Pulau Ngenang dan berdomisili di Kampung Melayu Batu Besar Nongsa, Batam yang merupakan tanah warisan orang tua sejak tahun 1928. Setelah menetap di tempat ini, Rahman mengganti nama kelompok musik ini dengan nama Orkes Melayu Pancaran Senja (Wawancara dengan Rahman, 15 Agustus 2016). Pemain group ini terdiri dari: Zulkarnain pemain akordion, Rahman pemain violin, Rosna penyanyi, Anwar pemain gendang bebano atau rebana dan sekaligus pembawa acara, Aad pemain gitar bass, dan Naim pemain gitar elektrik.
Upaya Rahman untuk mempertahankan grup ini agar tetap eksis adalah melakukan pertunjukan rutin di Pantai Melayu. Meskipun grup musik ini melakukan pertunjukan rutin, tetapi para pemusik tetap melakukan latihan rutin pula agar kekompakan bermain tetap terjaga. Di samping itu, latihan diperlukan jika ada lagu-lagu baru atau lagu Melayu lama yang sudah jarang dimainkan.

OMPS dalam setiap pertunjukannya mengikuti tata cara yang umum dilakukan oleh berbagai grup musik Melayu, yaitu menyajikan beragam rentak, seperti: langgam, rentak inang, rentak zapin, dan rentak joget. Pertunjukan diawali dari rentakinang bertempo sedang, kemudian diselingi dengan lagu-lagu rentak langgam bertempo lambat. Pertimbangan memulai pertunjukan dengan lagulagu rentak inang agar suasana bisa dibangun dari kondisi agak santai, sesuai pula dengan karakter tempo lagu-lagu rentak inang. Biasanya grupgrup musik Melayu ada pula melakukan dalam satu penyajian lagu, dimainkan dalam dua rentak dengan menggabungkan rentaklanggam dengan rentakinang. Teknis penggabungannya, setengah lagu atau kira-kira satu hingga dua pantun dimainkan dalam rentaklanggam, sedangkan pantun berikutnya dimainkan dalam rentakinang, sehingga dalam satu lagu akan terasa perpindahan tempo lagu dari lambat ke sedang.

Setelah lagu-lagu dalam rentak inang, selanjutnya dimainkan lagu-lagu dalam rentak zapin dengan ciri tempo sedikit lebih cepat dari tempo lagu-lagu dalam rentak inang. Lagu-lagu dalamrentak zapin merupakan lagu yang banyak berkembang dalam kawasan budaya Melayu Riau dan Riau Kepulauan. Bahkan lagu-lagu bergenre zapin dianggap sebagai ciri khasnya musik Melayu Riau dan Riau Kepulauan, karena lagu bergenre zapin dijadikan sebagai media dakwah penyiaran agama Islam di masa lalu. Lirik lagunya lebih banyak mengandung ajakan dan nasehat. Salah satu lagu bergenre zapin yang terkenal di kawasan budaya Melayu Riau dan Riau Kepulauan adalah Lancang Kuning. Lagu ini sering dimainkan oleh grup OMPS.

OMPS juga memainkan lagu-lagu zapin tradisi dan pop. Grup musik ini sudah melakukan pembaruan dari aspek instrumen dan lagu-lagu yang 
dimainkan. Mereka tidak terpaku pada lagu-lagu Melayu tradisi saja. Dalam konteks multikultural, etnisitas memasuki wilayah sosial ketika kelompok tersebut bersaing untuk mendapatkan sumber daya, manfaat, previlege berdasar atas hak mereka untuk membentuk diri mereka menjadi seperti yang mereka kehendaki (Cimardi, 2015: 54).

Seperti halnya dalam penyajian lagu-lagu dalam rentak inang, pada saat memainkan lagulagu rentak zapin, para pemusik OMPS dapat pula menggabungkan satu lagu dalam rentak langgam dengan rentak zapin, sehingga akan muncul lagu tanpa jeda dalam rentak langgam dan rentak zapin. Cara-cara seperti ini dilakukan untuk membangun dinamika pertunjukannya. Mereka tampak memainkan perasaan para penonton saat menikmati lagu; ketika lagu bergenre zapin dan juga bergenre inang atau mak inang, penonton masih bisa menikmati lagu dalam rentak langgam yang berkarakter melankolik.

Adapun suasana dan dinamika pertunjukan yang sangat penting dilakukan oleh OMPS adalah penyajian lagu-lagu dalam rentakjoget, karena sajian lagu pada ini bersifat rancak atau cepat dan dapat menghadirkan suasana gembira di antara pemusik dan penonton.Suasana gembira ini menjadi situasi yang ditunggu-tunggu dan dibutuhkan oleh pemusik dan penonton sebagai puncak suasana dan dramatik pertunjukan. Musik berada dalam tataran suprakultural sebagai medium komunikasi yang optimal (Cross, 2012: 96).

Lagu-lagu bergenre joget yang dimainkan oleh grup OMPS berasal dari berbagai lagu.Salah satu di antaranya adalah Bujang Telajak. Lagu ini mengisahkan seorang pemuda yang sudah berumur lanjut, tetapi belum menikah, disebut bujanglapok (bujang lapuk atau tidak laku). Hal yang menarik dari lagu ini adalah teks-teks atau lirik yang dinyanyikan menyindir dan mengisahkan nasib bujang lapuk. Lagu-lagu dalam rentak joget wajib hadir dalam setiap pertunjukan musiknya, karena pada lagu-lagu inilah para penonton dapat berpartisipasi berjoget di depan pentas sebagai respons senang dan gembira yang mereka rasakan. Puncak dari suasana itu akan muncul ungkapan eeewahh dari penyanyi, pemusik atau penonton sebagai wujud rasa estetis yang mereka alami.

\section{Estetika Eeewahb dalam Orkes Melayu Pancaran Senja}

Sebagaimana dinyatakan oleh Svasek bahwa proses pembentukan nilai estetik harus memperhatikan estetikanisasi untuk mengonseptualisasikan proses seseorang dalam menafsirkan pengalaman sensorik tertentu sebagai bagian yang berharga (Martarosa, 2016). Untuk mengalami peristiwa estetis dalam pertunjukan OMPS, penulis turut berpartisapasi menjadi pemain musik, yaitu se-bagai pemain drum set atau gendang bebano. Ketika bermain bersama group ini, penulis merasakan perbedaan rasa musikal rentak, khususnya rentak joget bersifat semarak, rancak, sesekali penulis disuruh menaikkan tempo permainan oleh Zulkarnaen pemain akordion. Ia memberi kode dan telapak tangan turun naik, agar penulis segera menaikkan tempo. Penulis juga menggunakan pancaindra dan kepekaan sensibilitas dalam mengamati realitas sosial ketika bermain bersama.

\section{Faktor-faktor Pembangun Eeewabh}

Seperti dijelaskan di depan, pertunjukan diawali dengan memainkan lagu-lagu rentak inang atau bertempo sedang sesekali memainkan rentak langgam. Suasana masih dalam keadaan tenang, namun anggota tubuh pemusik seperti kepala, badan, kaki sudah mulai bergerak kecil. Sementara penonton masih duduk santai pada tempat duduk yang berada di depan panggung pertunjukan, sembari bernyanyi kecil mengikuti lagu-lagu rentak inang yang sedang dimainkan. Seiring berjalannya waktu pertunjukan, penonton mulai dipengaruhi oleh efek musik, tampak anggota tubuh mereka bergerak-gerak kecil seperti kepala, badan, tangan, kaki pada saat duduk dan mendengarkan lagu-lagu rentak inang.

Suasana terasa semakin meriah dan gembira ketika mulai memainkan lagu-lagu rentak joget terus menerus, sehingga penonton bersemangat, antusias, interaksi canda tawa antara pemusik dan penonton pun terjadi. Kondisi ini membangun hasrat penonton berjoget di depan panggung pertunjukan tak tertahankan lagi. Mereka langsung 
berjoget tanpa ada paksaan dari siapa pun. Hal ini diperkuat oleh ajakan penyanyi kepada penonton melalui kata-kata, "mari berjoget bersama di depan panggung”. Rentakjoget bertempo rancak dan cepat memberikan gairah dan kegembiraan bersama sehingga meleburkan rasa yang dialami pemusik dan penonton (Gambar 1).

Ketika pertunjukan berlangsung, pantun demi pantun dari lirik lagu joget yang disajikan telah terlewati, seseorang bisa berasal dari pemusik, penyanyi, atau pun penonton akan mengalami situasi klimaks pada bagian interlude musik atau bagian tengah lagu rentak joget, maka secara spontan akan muncul ungkapan dengan kata: eeewahh, eeewahh, eeewahh. Kata eeewahh hanya bisa muncul jikalau seseorang benar-benar menikmati, merasakan, meresapi, dan menghayati lagu rentak joget. Merasakan, menghayati di sini dalam arti benar-benar menikmati alunan melebur menjadi satu dalam rentak joget. Peristiwa klimaks ini merupakan sublimasi diri atas permainan rentak joget, sehingga memberi daya tarik bagi penonton dan pemusik meresapi suasana rentak joget.

Efek dari rentak joget dapat dilihat dari aspek psikomotorik gerak tubuh bergerak joget berpasangan penuh semangat dalam hitungan per satu kali delapan (Wawancara dengan Suci Anggraini, 27 Juni 2017 di Batam). Kaki kiri bergerak satu langkah ke depan dengan ayunan tangan kanan. Begitu juga kaki kanan bergerak ke depan bersamaan ayunan tangan kiri. Joget bersifat fleksibel dan spontanitas bisa dilakukan sewaktu-waktu oleh siapa saja tanpa persiapan latihan tergantung gaya masing-masing penonton.

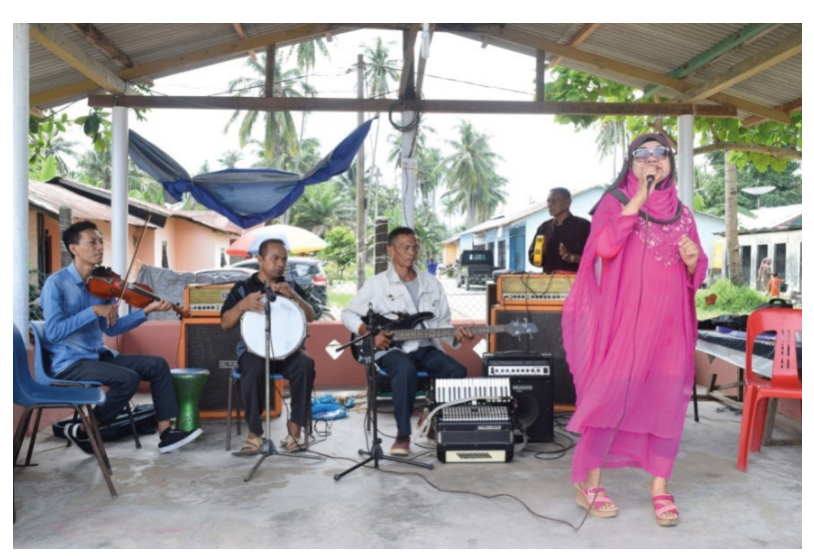

Gambar 1. Pertunjukan Musik Orkes Melayu Pancaran Senja di Pantai Melayu (Foto: Ihsan, 2016)
Sementara ekspresi wajah senyum, tertawa, senda gurau, sesama pemusik dan penonton merupakan nilai estetis dari rentak joget. Menurut Takari dan Dewi (2008: 138), rentak joget merupakan luapan kegembiraan dalam konsep musik Melayu (Gambar 2).

Ungkapan eeewahh sebagai reaksi psikologis atau fisologis terjadi dalam diri seseorang penyanyi dan penonton dalam rentak joget merupakan ekspresi emosi. Pengalaman diri seorang penyanyi dan penonton pada rentak joget dibentuk melalui interaksi pengetahuan, lingkungan keluarga dan lingkungan sosial Melayu Pesisir yang berarti kegembiraan. Senada dengan itu, Anwar, penyanyi OMPS menyatakan:

"Bahwa lagu pantun yang dimainkan pada waktu rentak joget dapat diterima sampai ke hati yang paling dalam oleh seorang penyanyi atau penonton. Maka ketika itu, tercetuslah eeewahh yang merupakan suatu bahasa yang menunjukkan suatu kepuasan dalam menikmati irama atau rentak joget itu sendiri. Secara tidak langsung seseorang itu berjoget atau bertandak atau berpasangan menciptakan gerak-gerik individu sendiri mengikuti tempo rentakjoget." (Wawancara dengan Anwar, 10 Agustus 2016 di Kampung Melayu).

OMPS menciptakan 'skenario' suasana eeewahh yang hadir dalam rentak joget memiliki daya tarik bagi penonton pada lokasi pertunjukan musik di Pantai Melayu. Transenden eeewahh mengalir terjadi dalam durasi lima atau enam detik, apabila benar-benar menghayati, merasakan,

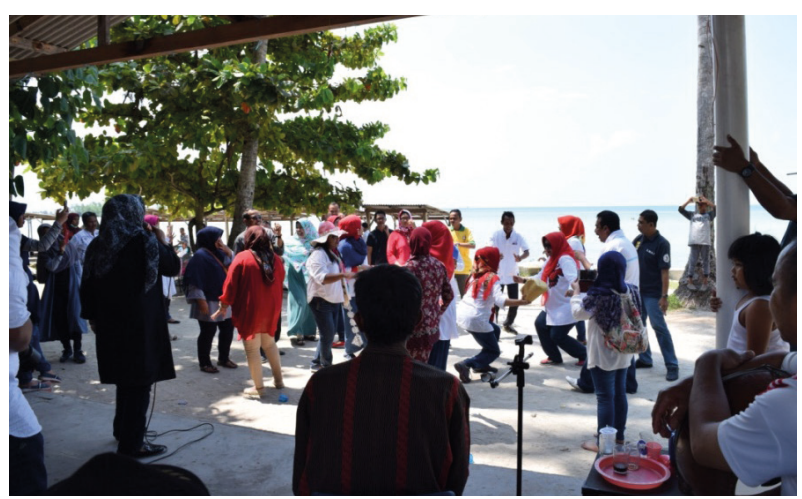

Gambar 2. Para Penonton Berjoget Mengikuti Irama Lagu Joget Pada Saat Pertunjukan Musik Orkes Melayu Pancaran Senja di Pantai Melayu (Foto: Ihsan, 23 Juni 2017) 
menikmati, meresapi rentak joget. Seiring dengan ini Sacks menyatakan:

"Ikatan ini dilakukan dengan irama bukan hanya didengar, tetapi diinternalisasikan secara identik dengan semua yang hadir. Irama mengubah pendengaran menjadi partisipan, menjadikan mendengar sebagai kegiatan aktif dan motorik, dan mensinkronkan otak dan pemikiran (dan, karena emosi selalu saling menjalin dengan musik, 'hati') dari semua yang telibat sangat sulit untuk tetap menjaga jarak" (Sack, 2013).

Tempo rentak joget yang dimainkan oleh OMPS pada metronom dengan kecepatan 120, susunan tangga nada tritonik atau tiga nada, logogenik, teks pantun terus menerus berubah, sementara melodi dan ritme tetap (Takari \& Dewi, 2008). Teks-teks pantun yang dilagukan sesuai pengetahuan penyanyi, irama bersifat patah (staccato), hiasan yang menguatkan nadanada pada pukulan kuat melodi dan ritme bersifat cepat atau rancak, gembira, senang, sukat permainan enam perdelapan, ekspresi penyanyi dan penonton gembira sembari berjoget berpasangan atau bertandak. Takari menyatakan:

"Sistem pertunjukan musik Melayu seperti, pertama, grenek nada hias yang rasanya relatif padat, nilai estetis musik ditonjolkan. Dua, cengkok menyatukan nada dalam bentuk legato. Tiga, patah hiasan yang menguatkan nada-nada pada pukulan kuat dan terakhir. Empat, rentak sebuah konsep perjalanan waktu dari musik yang dimainkan seperti sedang, cepat, dan lambat". (Takari \& Dewi, 2008)

\section{Musik dan Estetika Eeewahb}

Berikut pantun dalam rentak joget berjudul Bujang Telajak direkam 5 Desember 2016 di Pantai Melayu, Kampung Melayu Batu Besar, Batam.

Introduksi

Malang nasib si bujang lapok

Kemane pergi orang tak sibok

Malang nasib si bujang lapok

Kemane pergi orang tak sibok
Bujang ke bujang ternyate bungkok

Kalaulah malam berkawan nyamuk

Bujang ke bujang ternyate bungkok

Kalaulah malam berkawan nyamuk

Kedekak buah kedekik baling atas bukit

Tekak ndak bebini tapi duit sikit

Kedekak buah kedekik baling atas bukit

Kelahi laki bini gara gara kopi pahit

Interlude

Eeewahh

Malang nasib bujang telajak

Kemana pergi orang tak ajak

Malang Nasib bujang telajak

Kemana pergi orang tak ajak

Disuruh kawin die tak andak

Kalaulah malam berkawan cecak

Disuruh kawin die tak andak

Kalaulah malam berkawan cecak

Kedekak buah kedekik baling atas bukit

Tekak ndak bebini tapi duit sikiit

Kedekak buah kedekik baling atas bukit

Kelahi laki bini gara gara kopi pahit

Struktur melodi rentak joget pada lagu Bujang Telajak bergerak seperti teknik merajut, kontras kurang kelihatan dalam motif melodi yang diiringi oleh pola ritme. Pada instrumen lain yang membentuk satu ikatan harmoni. Instrumen violin cenderung berperan bermain melodi saat rentakjoget lagu Bujang Telajak. OMKS menggunakan tangga atau scale nada $\mathrm{C}$ mayor tritonik atau berjumlah tiga nada. Tonika dimulai akord A minor, akord $\mathrm{E}$ mayor, dan D minor. Pada bar kedua sampai bar kedelapan instrumen gitar membuat ritme pada ketukan singkop (up beat). Serangkaian pola ritme bass sebagai pergerakan akord dan penyeimbang pada ritme gendang bebano. Bar kesembilan dan kesepuluh gitar bersahut-sahutan dengan violin sebelum masuk pada bagian interlude (Notasi 1).

Pada bar dua puluh dua unisono violin dan vokal sampai pada bar tiga puluh satu. Instrumen bas dan akordion menjadi penahan pergerakan 
akord, selanjutnya eeewahh terjadi pada bar dua puluh Sembilan pada ketukan pertama sampai bar ketiga puluh ketukan kedua. Pada interlude inilah seorang penyanyi mengalami klimaks eeewahh durasi sekitar lima sampai enam detik.

Pada bar berikut kembali pada bentuk melodi awal periode pertama terjadi repetisi dari introduksi dan interlude. Jumlah bar lagu Bujang Telajak tiga puluh enam bar. Tinjauan dari sudut penyajian musik rentak joget OMKS pada analisis musik lagu Bujang Telajak berbentuk dua bagian atau dua periode introduksi dan interlude. Menurut jumlah kalimat maka dibedakan, satu bentuk lagu satu bagian: dengan satu kalimat, dua bentuk lagu dua bagian: dengan dua kalimat yang berlainan, tiga bentuk lagu tiga bagian: dengan tiga kalimat yang berlainan. Lagu yang berbentuk dua bagian bisa diurutkan dari kalimat A langsung masuk ke kalimat B. Lagu kalimat A diulang dengan variasi persis sama dengan sebelumnya walaupun teks pantun berbeda lalu masuk pada kalimat B.

Penyajian pantun pada lagu Bujang Telajak dari sudut musikologis logogenik atau teks berdasarkan pantun empat baris, kuatrain, terdiri dari sampiran dan dua baris isi (Takari dan Heristina, 2008: 139), sementara pada bagian eeewahh menggunakan teknik legato berarti satu tarikan nafas, tritonik terdiri dari tiga nada, ritme triplet enam perdelapan (Notasi 3).

\section{Konsep Sosial Eeeewah Masyarakat Kampung Melayu Batu Besar}

Pertunjukan OMKS dapat dianggap sebagai peristiwa yang menyadarkan individu dan kolektif masyarakat Kampung Melayu dalam menghargai dan menghormati nilai-nilai seni budaya Melayu. Praktik tindakan dalam menghargai dan menghormati seni budaya Melayu dibuktikan melalui apresiasi, partisipasi berkumpul bersama bermain musik atau menonton pada saatlatihan OMKS di rumah Rahman atau di Pantai Melayu.

Sebelum memainkan rentak joget ini, 'aktor' vokalis biasanya akan menyatakan rentak dan judul lagu. Ketika 'aktor' pemusik mendengar judul tersebut, pemusik merespons dan memainkan rentak joget. Ketika seorang penyanyi mengalami klimaks sehingga tercetus istilah eeewahh menunjukkan keadaan individu dan kolektif menjiwai, kagum, takjub, menikmati, rentakjoget

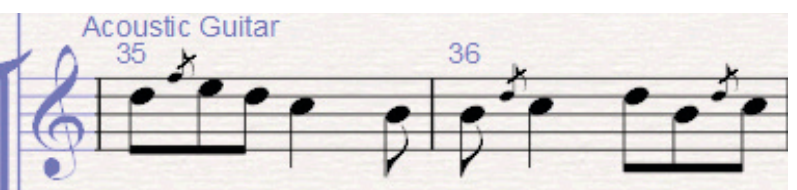

Bass Guitar
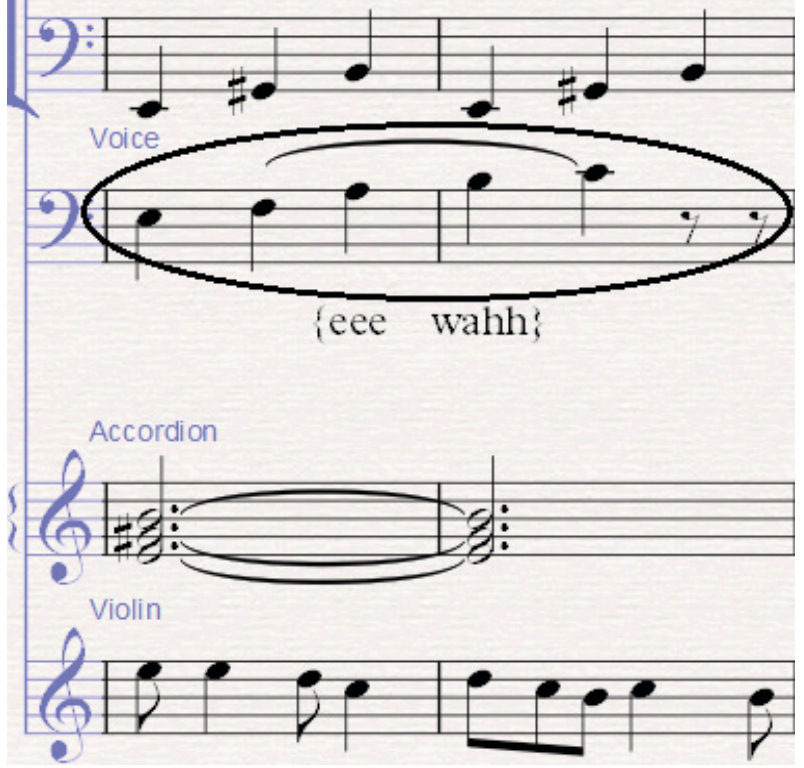

Notasi 2. Bagian Vokal Merasakan Klimaks Eeewahh

Notasi 1. Pola Ritme Gitar dan Violin 
yang memiliki pengetahuan kebiasaan masyarakat Kampung Melayu Batu Besar, Batam. Senada dengan pernyataan Smits bahwa:

Jika seseorang sekalipun tidak mendapatkan pendidikan musik formal, tetapi akan sangat berguna mengalami peristiwa musik secara langsung yang memenuhi aspek psikologi dan kultural, serta berbakat musikal. Sebab dalam pengalaman musik selalu diperlukan setidaknya suatu pengetahuan minimal tentang kebudayaan yang melingkupi musik tersebut (Narto, 2016: 83).

Aktor yang berinterakasi dari kecil hingga dewasa, menciptakan pengalaman pengetahuan dalam berkesenian Orkes Melayu. Senada dengan apa yang diutarakan Rahman.

"Saya bermain Orkes Melayu sejak kecil, saya melihat dan mendengar orang tua saya bermain biola, akordion, gendang bebano (rebana) dan gambus. Jadi, saya belajar dari almarhum orang tua. Beliau ketika hidup sering mengajak saya pentas kesana kemari” (Wawancara dengan Rahman, 15 Agustus 2016).

Biasanya sebelum latihan musik, pemusik mempersiapkan alat musik terlebih dahulu diletakkan di teras rumah Rahman. Penataan alat musik disesuaikan dengan posisinya, sembari obralan santai, serta menunggu pemusik yang lainnya. Obrolan santai ini saling tukar menukar informasi rutinitas pemusik-pemusik dalam kehidupan sosial. Efek dari obrolan santai ini, menjalin kedekatan emosional sesama pemusik, sehingga berpengaruh kepada kekompakan bermusik. Masyarakat Kampung Melayu Batu Besar yang mempunyai waktu luang biasanya datang untuk menonton proses latihan atau pun pertunjukan.

Melalui perjumpaan sosial terjalin interaksi sosial di antara pemusik, penonton, dan masyarakat.
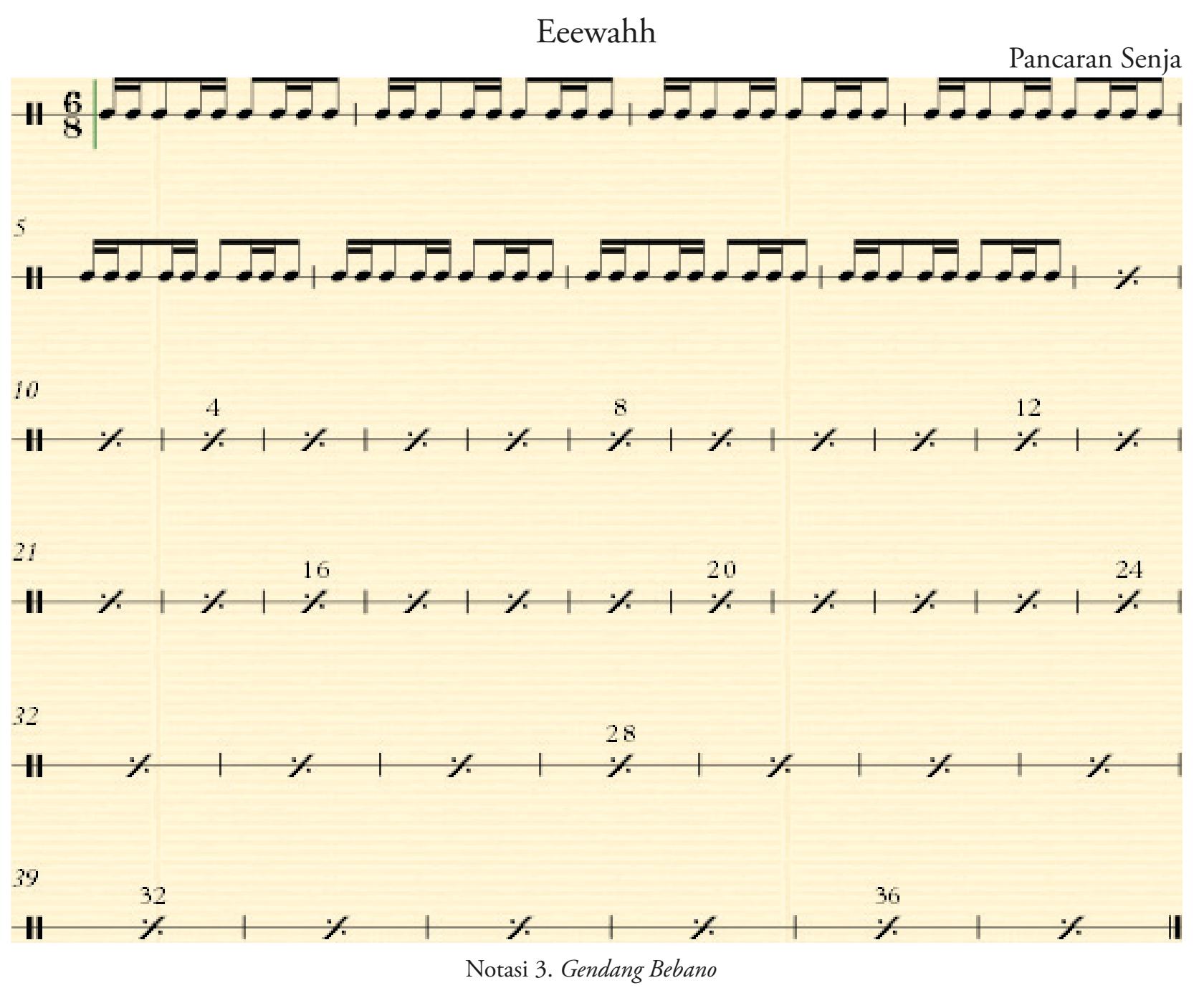
Peristiwa itu mewujudkan intergrasi sistem yang terjadi berarti hubungan timbal balik di antara para aktor atau kolektivitas (Giddens, 2010). Peristiwa eeewahh dalam kehidupan sehari-hari digambarkan melalui perlombaan jong (perlombaan perahu kecil yang berada dipinggir pantai). Ketika seorang individu masyarakat Kampung Melayu Batu Besar sedang menonton perlombaan jong. Bila mengalami keadaan kagum pada salah satu perahu jong biasanya terucap eee..wah..wah betuljong itu.

Eeewah merupakan representasi perilaku kegembiraan masyarakat Kampung Melayu Batu Besar. Kegiatan-kegiatan sosial, merewang, kerja kawin atau gotong royong untuk menjalin silatuhrahmi disambut dengan rasa gembira dan senang hati. Menyayah atau mengada-ada suatu kegiatan bercerita santai ketika masyarakat berkumpul di kedai kopi atau di rumah wargasengaja diciptakan agar suasana gembira ketika berkumpul bersama orang-orang Melayu. Kegiatan ini juga disebut borak-borak atau berbicara kosong atau lucu-lucuan sesama orang-orang Melayu.

\section{Penutup}

Estetika eeewahh merupakan satu kesatuan saling berhubungan erat dalam rentak joget. Dengan faktor pendukung seperti sukat enam perdelapan, kecepatan metronom 120 dengan tempo allegro, penyajian rentak joget lagu pantun Bujang Telajak tritonik yang menggunakan tiga tangga nada dimulai dari tonika A minor, E mayor, dan D minor, pantun bersifat logogenik atau teks terus menerus berubah sementara melodi dan ritme tetap sama. Masyarakat biasanya mengalami klimaks dibagian interlud pertama, kedua, atau ketiga tergantung pengalaman estetis penyanyi, pemusik, penonton, dan masyarakat. Ketika seorang penyanyi, pemusik, atau penonton mengucapkan eeewahh disebabkan mengalami keadaan mengalir menikmati situasi, sehingga eeewahh menjadi sosok tak terhindarkan, apabila seseorang benar-benar meresapi, menyelami, melebur bersama rentak joget, maka orang tersebut akan mengalami klimaks dalam waktu lima sampai enam detik. Istilah eeewahh juga representasi estetis emosi rasa kagum, senang, gembira, dan canda tawa dari perilaku-perilaku sosial masyarakat.
Peristiwa gembira juga digambarkan melalui kegiatan-kegiatan sosial seperti merewang atau gotong royong, menyayah atau mengada-ada, dan borak-borak atau bercerita lucu-lucuan.

\section{Kepustakaan}

Barnard, P. J. (2012). What Do We Mean by the Meanings of Music? Empirical Musicology Review, 7(1), 69-80.

Cimardi, L. (2015). From "tribes" to "region": Ethnicity and Musical Identity in Western Uganda. Periferia, 20(2), 44-59.

Cross, I. (2012). Musics, Cultures and Meanings: Music as Communication. Empirical Musicology Review, 7(1), 95-97.

Giddens, A. (2010). Teori Strukturasi Dasar-dasar Pembentukan Strukur Sosial Masyarakat. Yogyakarta: Pustaka Pelajar.

Lewis, J. (2012). Response to Richard Widdess: Music, Meaning, and Culture. Empirical Musicology Review, 7(1), 98-101.

Makale, H., \& Article, R. (2015). Ankara Halk Müziğinin Tarihsel ve Geleneksel Temelleri*, 3 (June), 1-12.

Martarosa. (2016). Apropriasi Musikal dan Estetika Musik Gamat. Resital Jurnal Seni Pertunjukan, 17(1), 19-29.

Nanni, M. (2014). Transmission of Musical Knowledge and History of European Culture in the Early Decades of the 15 Th Century. Musica Docta, 41-47.

Nita, A. M. (2011). Cultural Phenomena and Processes in Contemporary SocietyDeterminants of Cultural Policies. Revista de Stiinte Politice, (32), 1768-1774.

Pierobon, C. (2014). Political youth organisations, music and national identity in contemporary Russia. Studies of Transition States and Societies, 6(2), 39-56. https://doi.org/10.1002/ hlca.19890720505

Rasic, M. (2016). Antropologija muzike: paradigme in perspektive. Zbornik Radova Akademije Umetnosti, 2016(4), 133-144.

Rhoads, D. (2010). Biblical Performance Criticism: Performance as Research. Part of a Special Issue: Oral Tradition in Judaism, Christianity, 
and Islam, 25(1), 157-197.

Sack, O. (2013). Musikofilia: Kisah-kisah Tentang Musik dan Otak. Jakarta: Indeks.

Santi, M. (2017). Choir singing: Performing Identities and Loyalties. Musicological Annual, 53(2), 91. https://doi.org/10.4312/ mz.53.2.91-101

Takari, M., \& Dewi, H. (2008). Budaya Musik dan Tari Melayu Sumatra Utara. Medan: USU Press.

Ustun Topal, T., Korkut, A., \& Kiper, T. (2016). Local Identity Meeting With City: CittaslowSlow Cities Abstract. Idil Journal of Art and Language, 5(25), 1413-1430. https://doi. org/10.7816/idil-05-25-06

Widdess, R. (2012). Music, Meaning and Culture. Empirical Musicology Review, 7(1/2), 88-99. https://doi.org/10.5871/ bacad/9780197264195.003.0007

Yasin, F. (2015). Gaya Kehidupan Malam Remaja di Kota Padang: Suatu Kajian Subkultur di
Tempat Hiburan Malam Kota Padang. Jurnal Ilmu Sosial: Mamangan, 2(1), 59-71.

\section{Informan}

Anwar, 45 tahun, pekerjaan wirswasta, vokalis Orkes Melayu Pancaran Senja, alamat Teluk Nipah, Telaga Punggur, Batam.

Muhammad Saleh, 46 tahun, pekerjaan wiraswasta, pemain gitar bass, Orkes Melayu Pancaran Senja, alamat Teluk Mata Ikan, Kampung Melayu Batu Besar, Batam.

Rahman, 75 tahun, pekerjaan wiraswasta, pendiri grup dan sekaligus pemain biola Orkes Melayu Pancaran Senja, alamat Kampung Melayu Batu Besar, Batam.

Rosna, 60 tahun, pekerjaan wiraswasta, vokalis Orkes Melayu Pancaran Senja, alamat Kampung Telaga Punggur, Batam.

Suci Anggraini, 27 tahun, pekerjaan guru seni budaya, alamat Bengkong Permai, Batam. 